\title{
ISF Editorial 2020
}

\author{
R. Ramesh ${ }^{1,2} \cdot$ H. R. Rao ${ }^{1,2}$ \\ Published online: 5 February 2020 \\ (C) Springer Science+Business Media, LLC, part of Springer Nature 2020
}

Information Systems Frontiers, a Springer journal, began publication in July 1999 with a lead article by Nobel Laureate Kenneth Arrow on Team Theory and Distributed Processing (Arrow 1999). The journal has traditionally followed a format of four to five special issues or special sections per year and one or two general issues and has recently completed 20 years of publications (Beydoun et al. 2019).

Over the years, ISF has published special issues on wideranging cutting edge topics (Dwivedi et al. 2009). We provide a chronological list of all the special issues produced so far in the Appendix. Our guest editors come from all over the world, and include industry researchers as well as leading academics from institutions such as German Research Center for Artificial Intelligence (DFKI),Stanford University, University of Calgary, University of California at Berkeley; Texas A\&M University; SUNY at Buffalo; University of Maryland; NIST, HewlettPackard Labs, CalTech, IIT Delhi, Carnegie Mellon University, Philips Research, Delft University of Technology, Wuhan University of Technology, University of Arizona, Swansea University, City University of Hong Kong, IBM Research, University of Technology, Sydney, IIM Calcutta, etc., etc.

Information systems (IS) have emerged as critical resources to be leveraged for organizational productivities in most business, social and economic enterprises. The success of an enterprise is a function of how its information resources are designed, operated and managed. The major advances in Information Technology (IT) have elevated information systems to a position of strategic importance in the modern competitive enterprise. Consequently, research and innovation in IS/IT has acquired new levels of significance in academia, industry and the consumer community.

There is a growing demand to provide a thorough understanding of IS/IT frontiers along with its foundations to meet

\section{H. R. Rao}

mgmtrao@gmail.com

1 University at Buffalo, Buffalo, NY 14260, USA

2 University of Texas, San Antonio, Austin, TX, USA industry and academic needs. While the industry seeks to develop high performance IS/IT solutions to its business problems, academia looks to extend the reach of IS technology into new application domains. Information Systems Frontiers (ISF) has aimed to satisfy these needs by providing rigorous, timely research occurring at the forefront of the IS/IT field in both academia and the industry. This has been amply exemplified by the vast set of special issues produced over two decades of its publication that address cutting edge and emerging areas of IS/IT with a distinct multidisciplinary focus on IS/ IT research and application. Unlike the traditional publication philosophy of exclusively concentrating on either academic research or industrial innovation, ISF has focused on the integration of multi-disciplinary interfaces with IS and IT. Thus, ISF has acquired a global recognition as an international scholarly journal designed to bridge the contributing academic disciplines and link academia with industry. The central aim of ISF is to publish original, well-written, self-contained contributions that elucidate novel research and innovation in IS/IT which advance the field fundamentally and significantly. Published bi-monthly, ISF has significant accomplished the following goals and continues to develop its mission into new and higher levels of its focal areas and publishing philosophy:

- Provided a vibrant forum for both academicians and industry specialists to explore the multiple frontiers of the IS/IT field

- Brought innovative research on all aspects of IS/IT from analytical, behavioral and technological perspectives

- Fostered creativity at the emerging disciplinary interfaces leading to new frontiers in IS/IT research

- Enabled rapid dissemination of latest research and innovation, supported with a rigorous review processes

This issue of ISF marks an indeed important occasion in its journey: the successful culmination of 20 years of its publication and the start of a new road ahead in its mission. As a celebration of its accomplishments and a trendsetter for the next era in its journey, we present in this issue several invited 
articles from our distinguished advisory board members, in addition to regular papers. These articles include essays on the IS/IT productivity challenges by John Leslie King and Andrew J. Ehrenberg (2020); impact and intersection between the evolutionary quantum computing and the entangled web by Bernardo A. Huberman and Bob Lund (2020); a visionary essay on the emerging frontiers in smart environment and healthcare by Satyen Mukherjee (2020); cryptocurrencies and how they are changing the world of commerce by Xiaofan Li and Andrew B. Winston(2020); block chains in context by Andrew J. Ehrenberg and John Leslie King (2020) and an essay on reconciliation of privacy with preventive cybersecurity using the bright internet approach by Jae Kyu Lee, Y. Chang, H. Y. Kwon and B. Kim (2020). We hope you find these articles intellectually stimulating and which could prophetically open new and important areas of research for years to come.

Finally, we wish to thank all the authors, referees, guest editors, executive and coordinating editors and particularly the Advisory Editorial Board (past and present) for all their support over the years. In closing we also thank the editorial staff of Springer who have worked diligently to get the papers published in time.

\section{Appendix}

\section{Summary of Issues}

Vol. 1, No. 1 \& Vol. 1, No. 3, 1999

Vol. 1, No. 2, 1999

Vol. 1, No. 4, 1999

Vol. 2, No. 1, 2000

Vol. 2, No. 3, 2000 \& Vol. 2, No. 4, 2000

Vol. 3, No. 1, 2001 \& Vol. 3, No. 2, 2001

Vol. 3, No. 3, 2001

Vol. 3, No. 4, 2001

Vol. 4, No. 1, 2002

Vol. 4, No. 2, 2002

Vol. 4, No. 3, 2002

Vol. 4, No. 4, 2002 \& Vol. 5 No. 1, 2003

Vol. 5, No. 2, 2003

Vol. 5, No. 3, 2003

Vol. 5, No. 4, 2003
Inaugural issue

From E-Business to Electronic Commerce: Integration of web technologies with business models Guest Editor: M. Shaw, University of Illinois at Urbana-Champaign

From E-Business to Electronic Commerce: Integration of web technologies with business models Guest Editor: M. Shaw, University of Illinois at Urbana-Champaign

Knowledge Management and Organizational Memory

Guest Editors: A. Abecker, German Research Center for Artificial Intelligence (DFKI), Kaiserslautern, Germany; Stefan Decker, Stanford University; F. Maurer, University of Calgary, Alberta, Canada

Philosophical Reasoning in Information Systems Research

Guest Editors: C. West Churchman, University of California at Berkeley; J. Courtney, Texas A\&M University; G. L. Sanders, SUNY at Buffalo

Workflow Automation and Business Process Integration Guest Editors: Edward A. Stohr, New York University; J. Leon Zhao, University of Arizona

Supply Chain Systems: Research and Practice

Guest Editors: Saul Gass, University of Maryland; Al Jones, NIST

Next Generation Enterprises: Advances in Virtual organizations and

Mobile/Pervasive computing

Guest Editors: R. Ramesh \& H. Raghav Rao, SUNY Buffalo; Gabby Silberman, IBM Watson Center

Regular Issue

Co-Design of Business and IT Systems

Guest Editors: K. Liu \& Lily Sun, University of Reading, UK; K. Bennett, Durham University, UK

Advances in Software Engineering; Theory and Practice

Guest Editors: M. Bauer, University of Western Ontario; G. Hoffnagle \& G. Silberman, IBM; H. Johnson, $N R C$

Information Dynamics in the Networked World

Guest Editors: Bernardo Huberman Hewlett-Packard Labs; J. Ledyard, CalTech Advisory Editor:

Kenneth Arrow

IT Investment Payoff in E-Business Environments

Guest Editors: Rajiv Kohli, Trinity Health and University of Notre Dame; Susan Sherer, Lehigh University; A Baron, Cisco Systems

Business Applications of Uncertain Reasoning (Part I) and Informatics Support for Medical Research (Part II)

Guest Editors: Prakash P. Shenoy and Rajendra P. Srivastava, University of

Kansas; Harold P. Lehmann, Johns Hopkins University, Advisory Editor: Edward

Shortliffe, Columbia Presbyterian Medical Center, NY 
Vol. 6, No. 1, 2004

Vol. 6, No. 2, 2004

Vol. 6, No. 3, 2004

Vol. 6, No. 4, 2004

Vol. 7, No. 1, 2005

Vol. 7, No. 2, 2005

Vol. 7, No. 3, 2005

Vol. 7, No. 4 \&

No. 5, 2005

Vol. 8, No. 1, 2006

Vol. 8, No. 2, 2006

Vol. 8, No. 3, 2006

Vol. 8, No. 4, 2006

Vol. 8, No. 5, 2006

Vol. 9, No. 1, 2007

Vol. 9, No. 2 \& No. 3, 2007

Vol. 9, No. 4, 2007

Vol. 9, No. 5, 2007
Object-Oriented Client/Server Internet Environments

Guest Editor: Amjad Umar, Telcordia \& Fordham Graduate School of Business, NY

Cyberlaw: A Review of U.S. Criminal Civil and Evidence Law as It Applies to Computer Technology

Guest Editors: Susan W. Brenner, University of Dayton; Joseph J. Schwerha IV,

Carnegie Mellon University / Assistant District Attorney, Washington County Courthouse

Network Convergence: Issues, Trends, and Future

Guest Editors: S. Chatterjee, Claremont University; Amitava Dutta, George Mason University; VB. Chandhok, Nortel Networks

Industrial Information Systems Frontiers: Advances and Progress in the Pacific Rim

Guest Editors: Choon Seong Leem, Yonsei University, Korea; Matthew K.O. Lee, City University of Hong Kong; Sungwan Hong, LG-CNS, Korea

Computer Supported Collaborative Learning Requiring Immersive Presence (CSCLIP)

Guest Editors: Ramesh Sharda, Nicholas C. Romano, Jr. \& Joyce Lucca, Oklahoma State University; Lisa Neal, EDS

Mobile Computing and Communications: Systems, Models and Applications

Guest Editors: Giri K. Tayi, S. S. Ravi \& Sanjay Goel, State University of New York at Albany; Ram Ramanathan, BBN Technologies

Regular Issue

Advances in e-Technology and e-Services

Guest Editors: Soe-Tsyr Yuan, National Chengchi University, Taiwan, Jiming Liu, Baptist University, Hong Kong

Knowledge Discovery in High-Throughput Biological Domains

Guest Editors: Igor Jurisica, the Ontario Cancer Institute, UHN, Janice Glasgow, Queen's University, Ontario

Enterprise Architecture

Guest Editors: Hugo ter Doest, Marc Lankhorst, Henk Jonkers, Telematica Instituut,

Hans Bosma, Ordina Public Consulting, Roel Wieringa, University of Twente,

Farhad Arbab, Centrum voor Wiskunde en Informatica, Netherlands

Regular Issue

Web and Distributed Information Systems

Guest Editors: Muhammad Younas, Oxford Brookes University, UK, Kuo-Ming

Chao, Coventry University, UK, Ying Huang, IBM Watson Research Center, USA

Economic Aspects of Information Security

Guest Editors: Lawrence A. Gordon, University of Maryland, USA, Martin Loeb, University of Maryland,USA

Web Services to Services Computing: Technologies and Applications

Guest Editors: J. Leon Zhao \& Mohan Tanniru, University of Arizona, Liang-Jie Zhang, IBM Research

Enterprise Services Computing: Evolution and Challenges

Guest Editors: Donald W. Sparrow, MITRE, USA, Qing Li, City University of

Hong Kong, Hong Kong, Patrick C. K. Hung, University of Ontario Institute of Technology, Canada

Enterprise Distributed Computing: Model and Implementation

Guest Editors: Donald W. Sparrow, MITRE, USA, Qing Li, City University of

Hong Kong, Hong Kong, Patrick C. K. Hung, University of Ontario Institute of Technology, Canada

Secure Knowledge Management

Guest Editors: Nasir Memon, Polytechnic University, Six MetroTech Center, USA, 
Vol. 10, No. 1, 2008

Vol. 10, No. 2, 2008

Vol. 10, No. 3, 2008

Vol. 10, No. 4, 2008

Vol. 10, No. 5, 2008

Vol. 11, No. 1, 2009

Vol. 11, No. 2, 2009

Vol. 11, No. 3, 2009

Vol. 11, No. 4, 2009

Vol. 11, No. 5, 2009

Vol. 12, No. 1, 2010

Vol. 12, No. 2, 2010

Vol. 12, No. 3, 2010
Thomas Daniels, Iowa State University, USA

Regular Issue

Information Systems (IS) Sourcing

Guest Editors: Rudy Hirschheim, Louisiana State University, USA, Jens Dibbern,

University of Mannheim, Schloss, Germany, Armin Heinzl, University of Mannheim, Schloss, Germany

Decision Models for Information Systems Management

Guest Editors: Kweku-Muata Osei-Bryson, Virginia Commonwealth

University, USA, Ojelanki Ngwenyama, Ryerson University, Canada

Adoption and Use of Information \& Communication

Technologies (ICT) in the Residential/Household Context

Guest Editors: Yogesh K. Dwivedi, School of Business and Economics, UK, Michael D. Williams,

School of Business and Economics, UK, Viswanath Venkatesh, University of Arkansas, USA

Enterprise Information Systems (EIS)

Guest Editors: Ling Li, Old Dominion University, USA, Ricardo Valerdi,

Massachusetts Institute of Technology, USA, John N. Warfield, George Mason University, USA

Ambient Intelligence

Guest Editors: Satyen Mukherjee, Philips Research-North America, USA, Emile

Aarts, Philips Research, The Netherlands, Terry Doyle, Philips Research, The Netherlands

Information and Communications Technology for Development

Guest Editors: Balaji Parthasarathy, International Institute of Information Technology, Bangalore, India,

Krithi Ramamritham, Department of Computer

Science and Engineering, Indian Institute of Technology Bombay, Mumbai, India

Collaborative Business Process

Guest Editors: Chengfei Liu, Information and Communication Technologies, Swinburne

University of Technology, Melbourne, Australia, Qing Li, Department of Computer

Science, City University of Hong Kong, Tat Chee Avenue, Kowloon, Hong Kong, China Xiaohui Zhao,

Information and Communication Technologies, Swinburne University of Technology, Melbourne, Australia

Knowledge Discovery and Management in Biomedical Information Systems

Guest Editors: Ying Liu, Department of Industrial and Systems Engineering, The

Hong Kong Polytechnic University, Hong Kong, China, Lawrence Wing-Chi Chan,

The Hong Kong Polytechnic University, Hong Kong, China, Chi-Ren Shyu, University of Missouri-Columbia,

Columbia, USA, Ying Liu, University of Texas at Dallas, Dallas, USA

Intelligent Systems and Smart Homes

Guest Editors: Ching-Hsien Hsu, Chung Hua University, Taiwan, Hamid R.Arabnia,

The University of Georgia, USA, Jong Hyuk Park, Hanwha S\&C Co., Ltd., Korea

\section{Advances in Multi-Agency Disaster Management}

Guest Editors: Marijn Janssen, Delft University of Technology, Delft, The

Netherlands, JinKyu Lee, Oklahoma State University, Tulsa, OK, USA, Nitesh

Bharosa, Delft University of Technology, Delft, The Netherlands, Anthony

Cresswell, Center for Technology in Government, University at Albany-SUNY, Albany, NY, USA

Regular Issue

Technology Acceptance, Usage, and Competitive Advantage

Guest Editors: Devaki Rau, Northern Illinois University, USA, Thorvald Haerem,

Norwegian School of Management, Norway and University of California, USA, 
Vol. 12, No. 4, 2010

Vol. 12, No. 5, 2010

Vol. 13, No. 1, 2011

Vol. 13, No. 2, 2011

Vol. 13, No. 3, 2011

Vol. 13, No. 4, 2011

Vol. 13, No. 5, 2011

Vol. 14, No. 1, 2012

Vol. 14, No. 2, 2012

Vol. 14, No. 3, 2012

Vol. 14, No. 4, 2012

Vol. 14, No. 5, 2012

Vol. 15, No. 1, 2013
Gautam Ray, University of Minnesota, USA, Wei Zheng, Northern Illinois University, USA

Ethics and Information Systems

Guest Editors: Maria Carla Calzarossa, University of Pavia, Italy, Ivo De Lotto,

University of Pavia, Italy, Simon Rogerson, De Montfort University, UK

\section{Advances in RFID technology}

Guest Editors: Quan Z. Sheng, The University of Adelaide, Australia, Sherali Zeadally,

University of the District of Columbia, USA, Zongwei Luo, The University of Hong

Kong, China, Jen-Yao Chung, IBM T. J. Watson Research Center, USA, Zakaria Maamar, Zayed University, United Arab Emirates

\section{Terrorism Informatics}

Guest Editors: Hsinchun Chen, University of Arizona, USA, Yilu Zhou, George

Washington University, USA, Edna F. Reid, Catherine A. Larson, University of

Arizona, USA

Emerging Social and Legal Aspects of information systems with Web 2.0

Guest Editors: Dickson K. W. Chiu, Dickson Computer Systems, Hong Kong, Eleanna Kafeza, Athens University of Economics and Business, Greece, Patrick C. K. Hung, University of Ontario Institute of Technology, Canada

Global IT and IT-enabled services

Guest Editors: Michael Chau, The University of Hong Kong, Hong Kong, George L. Ball, Raytheon Missile Systems, USA, Jinghua Huang, Tsinghua University, China, Jian Chen, Tsinghua University,

China, J. Leon Zhao, City University of Hong Kong, Hong Kong

Regular Issue

Knowledge work and communication challenges in networked enterprises

Guest Editors: Joseph Barjis, Delft University of Technology, Netherlands, Ashish

Gupta, Minnesota State University Moorhead, USA, Ramesh Sharda, Oklahoma State University, USA

eHealth System Interoperability

Guest Editors: Jens Weber-Jahnke, University of Victoria, BC, Canada, Liam Peyton,

University of Ottawa, ON, Canada, Thodoros Topaloglou, Rouge Valley Health Systems, ON, Canada

Governance, risk and compliance: Applications in information systems Guest Editors: Dr. Shazia Sadiq, University of Queensland, Australia Dr. Michael zur

Muehlen, Stevens Institute of Technology, USA Dr. Marta Indulska, University of Queensland, Australia

Ubiquitous Multimedia Services

Guest Editors: Dr. Shiguo Lian, France Telecom $R \& D$

(Orange Labs), China Dr. Jean-Henry Morin, University of

Geneva, Switzerland, Dr. Stefanos Gritzalis, University of the

Aegean, Greece Dr. Gregory L. Heileman, University of New Mexico, USA

Intelligent Grid and Cloud Computing

Guest Editors: Dr. Jason J. Jung, Yeungnam University, South Korea

Dr. Yue -Shan Chang, National Taipei University, Taiwan

Dr. Ying Liu, Hong Kong Polytechnic University, Hong Kong

Dr. Chao-Chin Wu, National Changhua University of Education, Taiwan

Regular Issue

Security Management and Technologies for Protecting Against Internal Data Leakages

Guest Editors: Dr. Carly L. Huth, Carnegie Mellon University, USA

Dr. David W. Chadwick, University of Kent, UK

Dr. William R. Claycomb, Carnegie Mellon University, USA 
Vol. 15, No. 2, 2013

Vol. 15, No. 3, 2013

Vol. 15, No. 4, 2013

Vol. 15, No. 5, 2013

Vol. 16, No. 1, 2014

Vol. 16, No. 2, 2014

Vol. 16, No. 3, 2014

Vol. 16, No. 4, 2014

Vol. 16, No. 5, 2014

Vol. 17, No. 1, 2015

Vol. 17, No. 2, 2015

Vol. 17, No. 3, 2015

Vol. 17, No. 4, 2015

Vol. 17, No. 5, 2015
Dr. Ilsun You, Korean Bible University, Republic of Korea

Semantic Information Management

Guest Editors: Dr. Gabriele Kotsis, Johannes Kepler University, Austria

Dr. Ismail Khalil, Johannes Kepler University, Austria

\section{Business Intelligence and the Web}

Guest Editors: Dr. Jose -Norberto Mazón, University of Alicante, Spain

Dr. Irene Garrigós, University of Alicante, Spain

Dr. Florian Daniel, University of Trento, Italy

Dr. Malu Castellanos, HP Laboratories, USA

Information and Knowledge Management in Online Rich Presence Services

Guest Editors: Casey K. Fung, Boeing Research and Technology, USA Patrick C. K. Hung,

University of Ontario Institute of Technology, Canada

Green information systems \& technologies - this generation and beyond

Guest Editors: Joseph Sarkis, Worcester Polytechnic Institute, USA

Chulmo Koo, Kyung Hee University, South Korea

Richard T. Watson, University of Georgia, USA

Dynamic intelligence towards merging cloud and communication services

Guest Editors: Ching-Hsien Hsu, Chung Hua University, Taiwan

Jianhua Ma, Hosei University, Japan

Mohammad S. Obaidat, Monmouth University, USA

Advances in infrastructures and tools for multiagent systems

Guest Editors: Juan M. Alberola, Universitat Politecnica de

Valencia, Spain Vicent Botti, Universitat Politecnica de

Valencia, Spain Jose M. Such, Lancaster University, UK

A special section in memory of Paul Gray (1930-2012). The application of "futures research" to MIS

Guest Editors: Anat Hovav, Korea University, South Korea

Erran Carmel, American University, USA

Regular Issue

Information Reuse, Integration, and Reusable Systems

Guest Editors: Chengcui Zhang, The University of Alabama at

Birmingham, USA Elisa Bertino, Purdue University, USA

Bhavani Thuraisingham, The University of Texas at

Dallas, USA James Joshi, University of Pittsburgh,

USA

IS/IT Success and Failure

Guest Editors: Yogesh K. Dwivedi, Swansea University, UK

David Wastell, Nottingham University, UK

Helle Zinner Henriksen, Copenhagen Business School, Denmark

Rahul De', Indian Institute of Management Bangalore, India

Internet of Things (IoT) and Applications

Guest Editors: Pan Wang, Wuhan University of Technology, China

Ricardo Valerdi, University of Arizona, USA

Shangming Zhou, Swansea University, UK

Ling Li, Old Dominion University, USA

The role of information technology in service delivery

Guest Editors: Jaeki Song, Texas Tech University, USA

Jeff Baker, American University of Sharjah, UAE

Fred D. Davis, University of Arkansas, USA

Agreement Technologies

Guest Editors: Carlos Iván Chesñevar, Universidad Nacional del

Sur, Argentina Eva Onaindia, Universitat Politecnica de Valencia,

Spain Sascha Ossowski, University Rey Juan Carlos, Spain

George Vouros, University of Piraeus, Greece

Advances in secure knowledge management in the big data era 
Vol. 17, No. 6, 2015

Vol. 18, No. 1, 2016

Vol. 18, No. 2, 2016

Vol. 18, No. 3, 2016

Vol. 18, No. 4, 2016

Vol. 18, No. 5, 2016

Vol. 18, No. 6, 2016

Vol. 19, No. 1, 2017

Vol. 19, No. 2, 2017

Vol. 19, No. 4, 2017

Vol. 19, No. 5, 2017

Vol. 19, No. 6, 2017
Guest Editors: Chittaranjan Hota, BITS-Pilani,Hyderabad campus, India

Shambhu Upadhyaya, University at Buffalo, USA

Jamal Nazzal Al-Karaki, Abu Dhabi Polytechnic, UAE

Guest Advisory Editors: Nasir Memon, New York University, USA

Business Process Analytics

Guest Editors: Karl R. Lang, City University of New York, USA Vojislav B. Misic,

Ryerson University, Canada J. Leon Zhao, City University of Hong Kong, Hong Kong

\section{Collaboration technology in teams and organizations}

Guest Editors: Gert-Jan de Vreede, University of South Florida, USA

Pedro Antunes, Victoria University of Wellington, New Zealand

Julita Vassileva, University of Saskatchewan, Canada

Marco Aurélio Gerosa, University of São Paulo, Brazil

Kewen Wu, University of Saskatchewan, Canada

Big data and analytics in healthcare

Guest Editors: Atreyi Kankanhalli, National University of Singapore,

Singapore Jungpil Hahn, National University of Singapore, Singapore

Sharon Tan, National University of Singapore,

Singapore Gordon Gao, University of

Maryland, USA

Emerging service orientations and transformations (SOT)

Guest Editors: Haluk Demirkan, University of Washington-Tacoma, USA James C.

Spohrer, IBM Almaden Research Center, USA

Web of things

Guest Editors: Quan Z, Sheng, School of Computer Science, The University of Adelaide

Xue Li, School of Information Technology and Electrical Engineering, University of

Queensland Anne H. H. Ngu, Department of Computer Science, Texas State University

Yongrui Qin, School of Computing and Engineering, University of Huddersfield Dong Xie,

Department of Computer Science and Technology, Hunan University of Humanities, Science and Technology.

\section{Foundations of Reuse}

Guest Editors: Thouraya Bouabana-Tebibel, LCSI Laboratory Ecole nNationale

Supérieure d'Informatique Algiers, Algeria

Stuart H. Rubin, Space and Naval Warfare Systems Center Pacific, San Diego, USA

Knowledge and Competence Management: Developing Enterprise Solutions

Guest Editors: José Braga de Vasconcelos, Universidade Atlântica, Barcarena,

Portugal Chris Kimble, KEDGE Business School and Université Montpellier,

Talence, France Álvaro Rocha, University of Coimbra, Coimbra, Portugal

Regular Issue

Driving Public Innovation using Big and Open Linked Data

Guest Editors: Marijn Janssen, Delft University of Technology, The

Netherlands

David Konopnicki, IBM Haifa Research Lab, Israel

Teresa Harrison, University at Albany, USA

Jane L. Snowdon, IBM Corporation, USA

Adegboyega Ojo, National University of Ireland, Ireland

\section{Smart, Connected Hospitality and Tourism}

Guest Editors: Fevzi Okumus, The University of Central Florida

Cihan Cobanoglu, The University of South Florida Sarasota-Manatee

Francesco Ricci, Free University of Bozen-Bolzano

Chulmo Koo, Kyung Hee University

Computational Intelligence and Applications

Guest Editors: Vijayan Sugumaran, Oakland University, USA Geetha, T. V., Anna

University, India

Manjula, D, Anna University, India

Hema Gopal, Tata Consultancy Services, India

Big Data Analytics and Business Intelligence in Industry

Guest Editors: Shih-Chia Huang, Department of Electronic Engineering, National

Taipei University of Technology, Taipei City, Taiwan

Suzanne McIntosh, Courant Institute of Mathematical Sciences, Center for Data 
Vol. 20, No. 1, 2018

Vol. 20, No. 2, 2018

Vol. 20, No. 3, 2018

Vol. 20, No. 4, 2018

Vol. 20, No. 5, 2018

Vol. 21, No. 1, 2019

Vol. 21, No. 2, 2019
Science, New York University, New YorCenter for Urban Science and Progress, New York University, New York, USA

Patrick C. K. Hung, Faculty of Business and Information Technology, University of Ontario Institute of Technology, Oshawa, Canada

Special Section on Advances in Databases and Information Systems

Guest Editors: Ladjel Bellatreche, LIAS/ISAE-ENSMA - Poitiers University Poitiers

France Patrick Valduriez, INRIA and LIRMM Montpellier France

Tadeusz Morzy, Institute of Computing Science Poznan University of Technology Poznan Poland

Special Issue on Big Data \& Analytics for Societal Impact: Recent Research and Trends Guest Editors: Ashish Gupta, Auburn University Auburn USA

Amit Deokar, University of Massachusetts Lowell Lowell USA

Lakshmi Iyer, Appalachian State University Boone USA

Ramesh Sharda, Oklahoma State University Stillwater USA

Dave Schrader, Teradata University Network Dayton USA

Special Issue on Social Media: The Good, the Bad, and the Ugly

Guest Editors: Yogesh K. Dwivedi, Emerging Markets Research Centre (EMaRC),

School of Management Swansea University Swansea UK

Gerald Kelly, Sony UK Technology Centre Bridgend UK

Marijn Janssen, Faculty of Technology, Policy and Management Delft University of Technology Delft The Netherlands

Nripendra P Rana,

Emma L. Slade, School of Economics, Finance and Management University of Bristol Bristol UK

Marc Clement School of Management Swansea University, Bay Campus Swansea UK

Special Issue on Disaster Management And Information Systems: Insights To Emerging Challenges

Guest Editors: Ghassan Beydoun, School of System, Management and Leadership

University of Technology Sydney Ultimo Australia, Sergiu Dascalu, Department of Computer Science and Engineering University of Nevada Reno USA, Dale Dominey-Howes, School of Geosciences The University of Sydney Camperdown Australia, Andrew Sheehan, Flood Partnership | Waterways and Land Melbourne Water Melbourne Australia

Special Issue on Exploitation of Social Media for Emergency Relief and Preparedness: Recent Research and Trends

Guest Editors: Saptarshi Ghosh, IIT Kharagpur Kharagpur India

Kripabandhu Ghosh, IIT Kanpur Kanpur India

Debasis Ganguly, IBM Research Dublin Ireland

Tanmoy Chakraborty, IIIT Delhi Delhi India

Gareth J. F. Jones, Adapt Centre Dublin City University Dublin Ireland

Marie-Francine Moens, KU Leuven Leuven Belgium

Muhammad Imran, Qatar Computing Research Institute Al Rayyan Qatar

Special Issue on Recent Trends in Reuse and Integration

Guest Editors:

Thouraya Bouabana-Tebibel, Lydia Bouzar-Benlabiod, Laboratoire de la Communication dans les Systèmes Informatiques, Ecole nationale Supérieure d'Informatique, Algérie

Stuart H. Rubin, Space and Naval Warfare Systems Center Pacific, San Diego, CA, USA

Regular Issue
Vol. 21, No. 3, 2019

Vol. 21, No. 4, 2019 $\underline{\text { Special Issue on Digital Nations - Smart Cities, Innovation \& Sustainability }}$

Guest Editors:

Arpan Kumar Kar, Vigneswara Ilavarasan, M. P. Gupta, Department of Management Studies,

IIT Delhi, New Delhi, India

Marijn Janssen, Delft University of Technology, Delft, Netherlands

Ravi Kothari, Ashoka University, Sonipat, Indi

Special Section on Data Analytics in Behavioral Research

Guest Editors:

Luvai Motiwalla \& Amit V. Deokar, Department of Operations \& Information Systems, Manning

School of Business, University of Massachusetts Lowell, Lowell, MA, USA Surendra Sarnikar,

Department of Management, College of Business and Economics, California State University

East Bay, Hayward, CA, USA

Angelika Dimoka, Department of Management Information Systems, Fox School of Business, Temple

University, Philadelphia, PA, USA 
Vol. 21, No. 5, 2019

Vol. 21, No. 6, 2019

\section{Regular Issue}

Special Issue on Cyber Security, Privacy and Ethics of Information Systems Guest Editors:

Alessandro Acquisti, Carnegie Mellon University USA

Tamara Dinev, Florida Atlantic University USA

Mark Keil, Georgia State University USA

\section{References}

Arrow, K. J. (1999). Team theory and distributed processing: Surprise attack. Information Systems Frontiers, 1(1), 11-14.

Beydoun, G., Abedin, B., Merigó, J. M., \& Vera, M. (2019). Twenty years of information systems Frontiers. Information Systems Frontiers, 21(2), 485-494.

Dwivedi, Y. K., Lal, B., Mustafee, N., \& Williams, M. D. (2009). Profiling a decade of information systems Frontiers' research. Information Systems Frontiers, 11(1), 87-102.

Ehrenberg, A. J., \& King, J. L. (2020). Blockchain in context. Information Systems Frontiers, 22(1). https://doi.org/10.1007/ s10796-019-09946-6.

Huberman, B. A., \& Lund, B. (2020). A quantum router for the entangled web. Information Systems Frontiers, 22(1). https://doi.org/10.1007/ s10796-019-09955-5.

King, J. L., \& Ehrenberg, A. J. (2020). The productivity vampires. Information Systems Frontiers, 22(1). https://doi.org/10.1007/ s10796-019-09943-9.

Lee, J.K., Chang, Y., Kwon, H. Y and Kim, B. (2020) Reconciliation of privacy with preventive Cybersecurity: The bright internet approach. Information Systems Frontiers, 22(1). https://doi.org/10. 1007/s10796-020-09984-5.

Li, X., \& Whinston, A. B. (2020). Analyzing Cryptocurrencies. Information Systems Frontiers, 22(1). https://doi.org/10.1007/ s10796-019-09966-2.

Mukherjee, S. (2020). Emerging Frontiers in smart environment and healthcare - A vision. Information Systems Frontiers, 22(1). https://doi.org/10.1007/s10796-019-09965-3.

Publisher's Note Springer Nature remains neutral with regard to jurisdictional claims in published maps and institutional affiliations.
Ram Ramesh is professor of Management Science and Systems, SUNY at Buffalo. His research focuses on availability analytics and statistical modeling of cloud infrastructures. He serves as co-editor-in-chief of Information Systems Frontiers and an area editor of INFORMS Journal on Computing. His works extensively appear in ISR, INFORMS JOC, IEEE Transactions on Computers and IEEE Transactions on Knowledge and Data Engineering. His research has been funded by NSF, AFOSR, ARL, ARI, Google, Raytheon, Samsung and Westinghouse.

Dr. H. R. Rao is the AT\&T Distinguished Chair in Infrastructure Assurance and Security at The University of Texas at San Antonio College of Business. He also holds a courtesy appointment as full professor in the UTSA Department of Computer Science. Prior to working at UTSA, Professor Rao was the SUNY Distinguished Service Professor at the University at Buffalo. He graduated from Krannert Graduate School of Management at Purdue University.

Professor Rao was the inaugural recipient of The Bright Internet Award for his contributions to the information systems discipline by KMIS, the Korea Society of Management Information Systems. In 2018 Professor Rao was awarded the International Federation for Information Processing (IFIP) Outstanding Service Award for significant service contributions to the field of information systems and information systems security. In November 2016, Professor Rao received the prestigious Information Systems Society Distinguished Fellow Award (Class of 2016) for outstanding intellectual contributions to the information systems discipline.

Rao's work has received best paper and best paper runner up awards at ISR, AMCIS and ICIS. He has received funding for his research from the National Science Foundation, the Department of Defense and the Canadian Embassy. He also received the Fulbright fellowship. 